\title{
A basic serine protease from Paecilomyces lilacinus with biological activity against Meloidogyne hapla eggs
}

\author{
Peter J. M. Bonants, Paul F. L. Fitters, $\nmid$ Hans Thijs, $\ddagger$ Eefje den Belder, \\ Cees Waalwijk and Jan Willem D. M. Henfling $₫$
}

Author for correspondence: Peter J. M. Bonants.Tel: +31 8370 76213. Fax: +31 837010113. e-mail: BONANTS@IPO.AGRO.NL

DLO Research Institute for Plant Protection (IPO-DLO), PO Box 9060, $6700 \mathrm{GW}$ Wageningen, The Netherlands

\begin{abstract}
Scanning electron micrographs of the nematode-egg-parasitic fungus Paecilomyces lilacinus infecting eggs of the root-knot nematode Meloidogyne spp. suggested the involvement of lytic enzymes. When grown on a liquid mineral salts medium, supplemented with different substrates as the sole $\mathbf{N}$ and C-source, the fungus produced an extracellular protease. Colloidal chitin, vitellin and intact eggs of the root-knot nematode Meloidogyne hapla induced proteolytic activity that was repressed by glucose. The protease was partially purified from the culture filtrate by affinity chromatography. It has a molecular mass of $33.5 \mathrm{kDa}$, a pH optimum of $10 \cdot 3$, a temperature optimum of $60^{\circ} \mathrm{C}$ and an isoelectric point above pH 10.2. The enzyme was completely inhibited by PMSF. The amino acid sequence, as derived from the nucleotide sequence of a cDNA clone, had high homology with several subtilisin-like serine proteases. It was shown that the purified enzyme degrades vitellin. The protease quantitatively bound to nematode eggs, and eggs incubated with the purified protease eventually floated. Incubation of the purified protease with nematode eggs significantly influenced their development as demonstrated by time-lapse microscopy. Immature eggs were highly vulnerable to protease treatments, whereas those containing a juvenile were more resistant. In addition, hatched larvae were not visibly affected by the protease. It can be concluded that the serine protease might play a role in penetration of the fungus through the egg-shell of nematodes.
\end{abstract}

Keywords: Paecilomyces lilacinus, Meloidogyne hapla, protease, nematode-egg-parasitic fungus, cDNA sequence

\section{INTRODUCTION}

Nematodes are serious pests of many crops. There is growing opposition to chemical control of these pests because of unwanted environmental side-effects.

† Present address: St Patrick's College, Department of Biology, Maynooth, County Kildare, Ireland.

‡ Present address: Wageningen Agricultural University, Department of Genetics, Dreijenlaan 2, 6703 HA Wageningen, The Netherlands.

$\checkmark$ Present address: Netherlands Institute for Fisheries Research RIVO-DLO, PO BOX 68, 1970 AB IJmuiden, The Netherlands.

Abbreviations: $B P B$, bromophenol blue; MM, minimal medium; PVDF, polyvinylidene difluoride; SEM, scanning electron microscopy.

The GenBank accession number for the nucleotide sequence of the protease CDNA clone pSP-3 reported in this paper is L29262.
Alternatives for these control measures are being developed, one of which may be biological control by parasitic fungi. Many fungi parasitize plant-parasitic nematodes, either by capturing nematodes or by parasitizing their eggs.

Several fungi are capable of penetrating nematode eggs. The fungus Dactylella oviparasitica grows rapidly through egg-masses of the root-knot nematode Meloidogyne spp. and hyphae of the fungus penetrate egg-shells (Stirling \& Mankau, 1979). Fungal egg-parasites, isolated from eggs of the cyst nematode Heterodera avenae, were investigated with respect to their ability to infect cyst nematode eggs of $H$. schachtii by Dackman et al. (1989). Of these isolates, $V$ erticillium suchlasporium appeared to be most effective. $V$. chlamydosporium was evaluated in vitro for its ability to 
parasitize eggs of $M$. arenaria by Morgan-Jones et al. (1983). It prevented egg hatching, and colonized eggs by hyphal penetration.

The mechanism of the infection process by egg-parasitic fungi may be either mechanical or enzymic or both. To date few attempts have been made to determine the effects of purified fungal enzymes on the egg-shell of the rootknot nematode. Stirling \& Mankau (1979) studied the enzymes of nematode-egg-parasitic fungus $D$. oviparasitica in liquid culture supplemented with colloidal chitin. These authors found chitinase activity and suggested a role for this enzyme in penetrating the egg-shell, which consists partly of chitin (Wharton, 1980). Whether other enzymes were involved remained unclear. Dackman et al. (1989) showed a correlation between the percentage of infected eggs of $H$. schacbtii and chitinase and protease activity. A purified extracellular protease from $V$. suchlasporium was capable of degrading a protein from the egg-shell of cyst nematodes (Lopez-Llorca, 1990). The presence of this protease in infected nematode eggs could be determined by immunocytochemistry, supporting its role in pathogenesis (Lopez-Llorca \& Robertson, 1992).

We have focused our attention on the nematode-eggparasite Paecilomyces lilacinus, which is able to degrade the egg-shell of the root-knot nematode Meloidogyne spp. (Dunn et al., 1982) and which has been used as a biological control agent in Peru and in the Philippines (Jatala et al., 1980; Cabanillas \& Barker, 1989; Cabanillas et al., 1989; Gaspard et al., 1990; Zaki \& Bhatti, 1990).

The egg-shell of the root-knot nematode $M$. hapla consists of at least $40 \%$ protein (Wharton, 1980). The outer layer of the egg-shell consists of the protein vitellin, which forms the first barrier to the fungus. The purpose of the present study was to investigate whether a protease could be isolated that might play a role in the penetration of eggshells and therefore would be involved in pathogenesis. One serine protease, which was specifically induced, was purified and characterized and the biological effect of this enzyme on nematode eggs was studied microscopically.

\section{METHODS}

Organisms and culture conditions. Paecilomyces lilacinus (Thom.) Samson (CBS 143.75) was cultured in minimal medium (MM; $4.56 \mathrm{~g} \mathrm{~K}_{2} \mathrm{HPO}_{4}, 2.77 \mathrm{~g} \mathrm{KH}_{2} \mathrm{PO}_{4}, 0.5 \mathrm{~g} \mathrm{MgSO}_{4} .7 \mathrm{H}_{2} \mathrm{O}$ and $0.5 \mathrm{~g} \mathrm{KCl} \mathrm{l}^{-1}, \mathrm{pH} \mathrm{6.0)} \mathrm{as} \mathrm{described} \mathrm{by} \mathrm{Fitters} \mathrm{\&} \mathrm{den} \mathrm{Belder}$ (1993). The following substrates were added either alone or in combination: vitellin $[0.2 \%(\mathrm{w} / \mathrm{v})$; Sigma $]$, colloidal chitin $[0.2 \%$ and $1.0 \%(\mathrm{w} / \mathrm{v})$; prepared according to the method of Lingappa \& Lockwood (1962) using chitin from Sigma], rootknot nematode eggs $\left(250000 \mathrm{ml}^{-1}\right.$ ), nitrogen (N) (as $2.0 \mathrm{~g}$ asparagine $\left.+2.0 \mathrm{~g} \mathrm{NaNO}_{3} \mathrm{l}^{-1}\right)$ and glucose $(\mathrm{G})[2 \cdot 0 \%(\mathrm{w} / \mathrm{v})]$. Culture filtrates were obtained by centrifuging liquid cultures for $45 \mathrm{~min}$ at 9000 r.p.m. The supernatant was subsequently concentrated on an Amicon YM-10 filter and clarified through a $0.22 \mu \mathrm{m}$ filter (Schleicher \& Schuell). Pellets were freeze-dried and weighed.

Eggs of the root-knot nematode $M$. bapla were isolated from egg-masses on roots of infected tomato plants (Lycopersicon esculentum $\mathrm{cv}$. Moneymaker) as described by Fitters \& den
Belder (1993). Scanning electron microscopy was performed on root-knot nematode eggs of $M$. hapla and the fungus $P$. lilacinus as described by den Belder et al. (1993).

Purification and characterization of protease. Protease activity was determined essentially according to Rinderknecht $e t$ al. (1968). Protease activity of the sample was measured in duplicate, averaged and expressed as $A_{595}$ units $\mathrm{ml}^{-1} \mathrm{~h}^{-1}$. Variation between duplicates was less than $10 \%$. Protein content of the samples was determined according to the method of Bradford (1976), using BSA as the standard. The concentrated culture filtrate was dialysed overnight at $4{ }^{\circ} \mathrm{C}$ against equilibration buffer $(100 \mathrm{mM}$ ammonium acetate, $10 \mathrm{mM} \mathrm{CaCl}$, $\mathrm{pH} \mathrm{6.5)} \mathrm{and} \mathrm{applied} \mathrm{to} \mathrm{an} \mathrm{equilibrated} 2 \mathrm{ml}$ bacitracin-Sepharose column. The bacitracin-Sepharose was prepared as described by Stepanov \& Rudenskaya (1983). After washing the column with $100 \mathrm{mM}$ ammonium acetate buffer $\mathrm{pH} 6.5$, the bound protease was eluted with elution buffer $(100 \mathrm{mM}$ ammonium acetate, $1 \mathrm{M}$ $\mathrm{NaCl}, 25 \%$ 2-propanol, $\mathrm{pH} 6.5)$. Fractions of $1 \mathrm{ml}$ were collected and tested for proteolytic activity. Positive fractions were pooled and dialysed against $100 \mathrm{mM}$ ammonium acetate $\mathrm{pH} 6.5$.

After SDS-PAGE by the method of Laemmli (1970), gels were stained with silver (Morrissey, 1981) and dried. Molecular mass was determined using Bio-Rad low-range standards.

The optimal $\mathrm{pH}$ and temperature for protease activity was determined in triplicate in buffers with $\mathrm{pH}$ values ranging from 4 to 12.5 and at different temperatures $\left(30^{\circ} \mathrm{C}-80^{\circ} \mathrm{C}\right)$. The isoelectric point of the protease was determined by chromatofocusing (FPLC, Mono P HR 5/5; Pharmacia).

The purified enzyme was incubated for $40 \mathrm{~min}$ at $4{ }^{\circ} \mathrm{C}$ with individual inhibitors and subsequently protease activity was determined. Protease activity was expressed as a percentage of the activity found in the absence of inhibitor. The final concentration of inhibitor was $1 \mathrm{mM}$. Vitellin $(1 \mathrm{mg})$ was incubated with the purified protease or with buffer as control for $16 \mathrm{~h}$ at $37^{\circ} \mathrm{C}$ in $100 \mathrm{mM}$ sodium acetate buffer $\mathrm{pH} 6.0$ in $1 \mathrm{ml}$ tubes. After incubation the samples were centrifuged $(1 \mathrm{~min}$ at 14000 r.p.m.) and the $A_{280}$ of the supernatant was measured.

Isolation and sequencing of protease CDNA clone. To construct a cDNA library of $P$. lilacinus, mycelium was grown for $48 \mathrm{~h}$ at $30^{\circ} \mathrm{C}$ and 150 r.p.m. in minimal medium (MM) containing $4 \times 10^{8}$ nematode eggs $1^{-1}$. As an inoculum $4 \times 10^{10}$ conidia $1^{-1}$ were used. From the nucleic acid fraction, mRNAs were isolated using the polyA Ttract system (Promega). Using the lambda ZAP system (Stratagene) a cDNA library was constructed that contained 500000 clones.

The purified protease was blotted from SDS-PAGE gels to PVDF membrane with the Bio-Rad Mini-PROTEAN blotting unit $\left(1.5 \mathrm{~h}, 100 \mathrm{~V}, 4^{\circ} \mathrm{C}\right.$, transfer buffer consisting of $25 \mathrm{mM}$ Tris $/ \mathrm{HCl} \mathrm{pH} 8.3,192 \mathrm{mM}$ glycine, $20 \%$ methanol). The membrane was stained with Coomassie Brilliant Blue. The protease band was excised and the $16 \mathrm{~N}$-terminal amino acids were determined by Eurosequence (Groningen).

Primer A (5'-GCITAYACICARCARCCIGGIGCICC-3') was designed from a unique sequence in the $\mathrm{N}$-terminal part of the $P$. lilacinus protease as compared to the $\mathrm{N}$-terminal part of other subtilisin serine proteases and primer B (5'-G'TICCIGCRCARTGIGTICCRTGICCRT'TICC-3') was deduced from the conserved part around the histidine residue in the catalytic active site of protease B of Saccharomyces cerevisiae (Moehle et al., 1987) and proteinase K of Tritirachium album (Jany et al., 1986). The PCR mixture of $100 \mu \mathrm{l}$ contained $50 \mathrm{mM} \mathrm{KCl}, 10 \mathrm{mM}$ Tris/ $\mathrm{HCl}(\mathrm{pH} 8.3), 0.5 \mathrm{mM} \mathrm{MgCl}, 100 \mu \mathrm{M}$ of each dNTP, 
400 ng genomic DNA from $P$. lilacinus, $2.5 \mathrm{U}$ AmpliTaq DNA polymerase (Perkin Elmer Cetus) and 100 pmol of both primers. Each of the 35 amplification cycles included a denaturation step at $94{ }^{\circ} \mathrm{C}$ for $1 \mathrm{~min}$, an annealing step at $60^{\circ} \mathrm{C}$ for $2 \mathrm{~min}$ and a chain-elongation step at $72^{\circ} \mathrm{C}$ for $3 \mathrm{~min}$. The amplification reaction was preceded by a denaturing step at $94^{\circ} \mathrm{C}$ for $0.5 \mathrm{~min}$, and the elongation step of the last cycle was extended to $5 \mathrm{~min}$. Identification of protease cDNA clones was done by using the PCR product as a probe (Sambrook et al., 1989). The inserts of hybridizing plaques were excised in vivo with the Stratagene lambda ZAP system. The resulting plasmids were analysed with restriction enzymes and the nucleotide sequence of the clone containing the largest insert ( $\pm 1300 \mathrm{bp}$ ) was determined using the Taq dye primer sequencing kit (Applied Biosystems), the TaqTrack sequencing kit (Promega) and the T7 sequencing kit and the Automated Laser Fluorescent DNA Sequencer (Pharmacia).

Biological activity. Root-knot nematode eggs were incubated at room temperature with the purified protease in $1.5 \mathrm{ml}$ Eppendorf tubes in $100 \mathrm{mM}$ potassium phosphate buffer $\mathrm{pH} 7 \cdot 0$ and shaken at 150 r.p.m. for $30 \mathrm{~min}$. At several time points, $200 \mu \mathrm{l}$ samples were taken and centrifuged for $1 \mathrm{~min}$ at 14000 r.p.m. Protease activity was determined and SDS-PAGE was performed on the supernatant as described above. The bound enzyme was eluted from the nematode eggs with $100 \mathrm{mM}$ potassium phosphate buffer ( $\mathrm{pH} 7 \cdot 0$ ) containing $0.5 \mathrm{M} \mathrm{NaCl}$.

The bioassays were performed in 24-well microtitre plates. All solutions used were filter-sterilized through $0.2 \mu \mathrm{m}$ filters (Schleicher \& Schuell). Approximately 50 eggs at different stages of development were incubated in $500 \mu \mathrm{l}$ in a well. Microtitre plates were placed in the dark at $25^{\circ} \mathrm{C}$. All assays were done in triplicate. Effects were monitored at different time intervals with an inverted light microscope (Axiovert 10, Zeiss).

The pilot bioassay consisted of treatment with culture filtrate of $P$. lilacinus grown on vitellin and a control $(10 \mathrm{mM}$ potassium phosphate buffer, $\mathrm{pH} 6.0$ ). The protease activity and protein content of the culture filtrate was $86 A_{595}$ units $\mathrm{ml}^{-1} \mathrm{~h}^{-1}$ and $304 \mu \mathrm{g} \mathrm{ml}^{-1}$, respectively. The development of the eggs was studied using the time-lapse method of Fitters \& den Belder (1993). In the second bioassay the effects of culture filtrate of $P$. lilacinus grown on vitellin and the purified protease isolated from culture filtrates of $P$. lilacinus grown on vitellin or on chitin were compared with the control $(10 \mathrm{mM}$ potassium phosphate buffer, $\mathrm{pH} 6.0$ ). Protease activities were 104, 52 and $108 A_{595}$ units $\mathrm{ml}^{-1} \mathrm{~h}^{-1}$, respectively.

Data were analysed with a Generalized Linear Model (McCullagh \& Nelder, 1989), followed by analysis of deviance for quantal data, and when appropriate subjected to a Student's $t$-test for pairwise comparison of treatments on a logarithmic scale. All tests were performed with a significance level of $\alpha=0 \cdot 05$. Analysis was carried out with Genstat (Genstat 5 Committee, 1987).

\section{RESULTS}

\section{Induction of protease}

Cryo-SEM studies have shown that when eggs of the root-knot nematode $M$. hapla are infected with P. lilacinus, the egg-shell is partially dissolved, suggesting the involvement of lytic enzymes. Because the egg-shell consists of $40 \%$ protein and its outer layer is composed of vitellin, we focused on proteases as the major enzyme in parasitism.

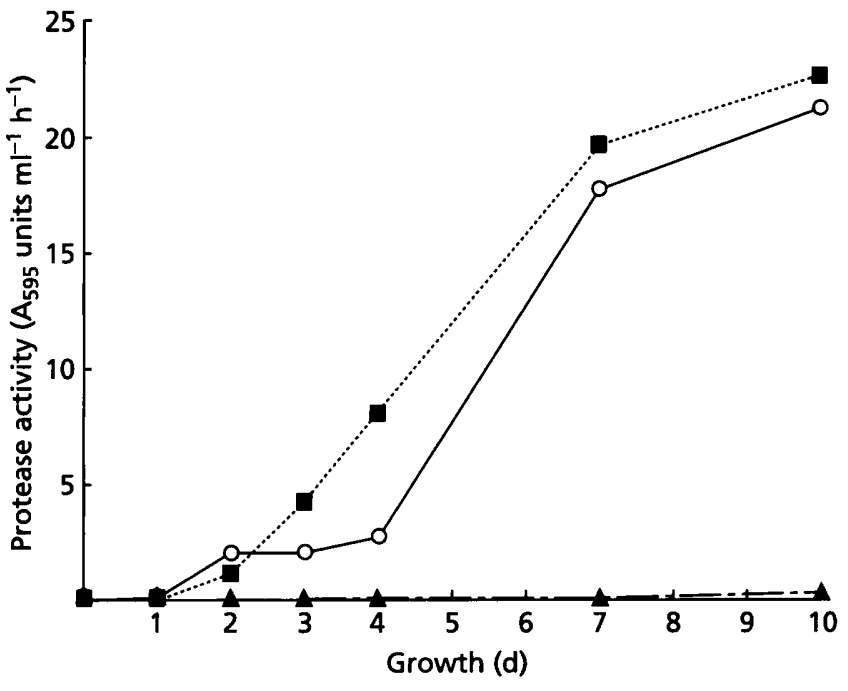

Fig. 1. Protease activity of culture filtrates of $P$. lilacinus $\left(10^{8}\right.$ conidia) in $10 \mathrm{ml}$ liquid $\mathrm{MM}(\Delta)$ to which $2.5 \times 10^{6} \mathrm{M}$. hapla eggs $(\square)$ or nitrogen $\left[\mathrm{NaNO}_{3}(0.2 \%)+\right.$ asparagine $\left.(0.2 \%)\right]+$ glucose $(2.0 \%)(O)$ were added.

P. lilacinus grown for $3 \mathrm{~d}$ at $25^{\circ} \mathrm{C}$ on solid agar containing gelatin showed haloes, suggesting the presence of extracellular protease activity (data not shown). The production of extracellular protease(s) by the fungus was further investigated in liquid MM supplemented with various $\mathrm{C}$ - and $\mathrm{N}$-sources. Protease activity in the culture filtrate was monitored at daily intervals following inoculation with conidia of $P$. lilacinus. From day 2 onward, proteolytic activity in MM cultures containing eggs (MME) increased at least until $10 \mathrm{~d}$ after inoculation (Fig. 1). If more eggs were added as substrate more extracellular protease activity was found (data not shown). Without Cor $\mathrm{N}$-sources present in the MM there was no growth and no proteolytic activity in the culture filtrate. Addition of chitin or vitellin as substrate to cultures of $P$. lilacinus in MM also resulted in induction of proteolytic activity. Table 1 shows protease activity and protein content of the filtrate of different cultures of $P$. lilacinus after $4 \mathrm{~d}$ growth. The highest protease activity was observed with vitellin as substrate. Specific protease activity [protease activity ( $\mu \mathrm{g}$ protein $)^{-1}$ ] was high in cultures containing eggs or vitellin as substrate. With vitellin as substrate specific protease activity was underestimated because the added amount of vitellin was not taken into account. MM supplemented with $N$ and $G$ also showed increased protease activity. However, protease activity only increased after day 4 (Fig. $1)$, when all the added glucose was consumed. This was substantiated by the fact that under inducing conditions daily addition of glucose completely repressed the induction of the protease (data not shown).

\section{Purification of protease}

The SDS-PAGE patterns of the culture filtrates showed that the fungus produced many different proteins (Fig. 2). Moreover, a large number of proteins appeared to be 
Table 1. Protease activity and protein content of concentrated filtrates of 4-d-old cultures of $P$. lilacinus ( $2 \times 10^{8}$ conidia) in $200 \mathrm{ml}$ liquid $\mathrm{MM}$ to which different substrates were added

\begin{tabular}{|c|c|c|c|}
\hline $\begin{array}{l}\text { Minimal medium } \\
\quad+ \\
\text { the following substrates: }\end{array}$ & $\begin{array}{c}\text { Protease activity } \\
\left(A_{595} \text { units } \mathrm{ml}^{-1} \mathrm{~h}^{-1}\right)\end{array}$ & $\begin{array}{l}\text { Protein content } \\
\qquad\left(\mu \mathrm{g} \mathrm{ml}^{-1}\right)\end{array}$ & $\begin{array}{c}\text { Specific protease } \\
\text { activity } \\
\left(A_{595} \text { units } \mu g^{-1} h^{-1}\right)\end{array}$ \\
\hline $\begin{array}{l}\text { Nitrogen }\left[\mathrm{NaNO}_{3}(0 \cdot 2 \%)+\right. \\
\text { asparagine }(0 \cdot 2 \%)]+ \\
\text { glucose }(2 \cdot 0 \%)\end{array}$ & $4 \cdot 24$ & $47 \cdot 5$ & 0.089 \\
\hline Chitin $(0 \cdot 2 \%)$ & $23 \cdot 85$ & $104 \cdot 2$ & $0 \cdot 229$ \\
\hline $\begin{array}{l}\text { Meloidogyne bapla } \\
\text { eggs }\left(2.25 \times 10^{6}\right)\end{array}$ & $21 \cdot 83$ & $35 \cdot 3$ & $0 \cdot 618$ \\
\hline Vitellin $(0 \cdot 2 \%)$ & $93 \cdot 79$ & $303 \cdot 9 *$ & $0 \cdot 309$ \\
\hline
\end{tabular}

*Including the added vitellin.

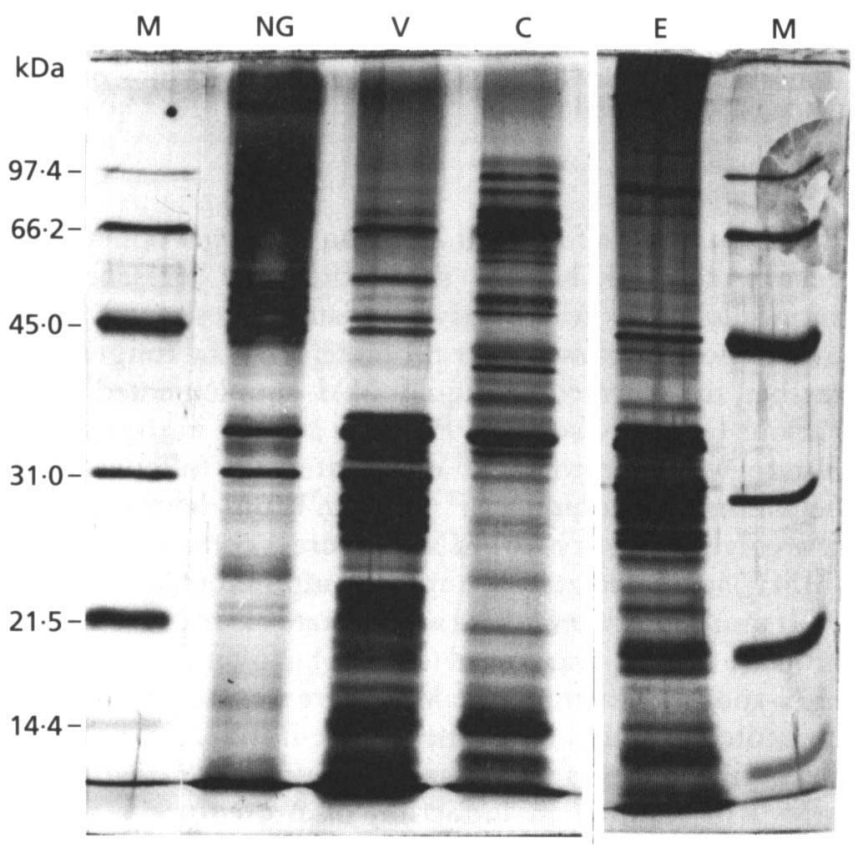

Fig. 2. SDS-PAGE patterns of filtrates of 4-d-old cultures of $P$. lilacinus in MM to which different substrates were added. Lane NG, nitrogen + glucose; lane V, vitellin; lane $C$, chitin; lane $E$, eggs; lane $M$, molecular mass markers (sizes in $\mathrm{kDa}$ ).

induced upon addition of different substrates to the medium. With $\mathrm{N}$ and $\mathrm{G}$ as substrates there were several bands on SDS-polyacrylamide gels, but with vitellin or chitin unique, more complex patterns were observed. The protein pattern of the culture filtrate with nematode eggs as substrate resembled that of the culture filtrate with vitellin as substrate (Fig. 2, lanes E and V, respectively). To identify the type of proteases present in the culture filtrate, the proteolytic activity was measured in the presence of several protease inhibitors. Almost complete inhibition of the proteolytic activity in the culture filtrate was observed with PMSF, indicating that most of the protease activity present belonged to the serine protease class.

The first attempt to purify the serine protease(s) was by means of a benzamidine-Sepharose column, an affinity resin for class I serine proteases. Since no proteolytic activity bound, it was concluded that the protease belongs to the class of subtilisin-like serine proteases. Stepanov \& Rudenskaya (1983) showed that this class of proteases binds to bacitracin-Sepharose. Using this material the protease was purified from a culture filtrate of the fungus grown with chitin as substrate. Protease activity of the eluted fractions was measured and the fractions were subjected to SDS-PAGE. The SDS-PAGE pattern of the fraction from the affinity purification step with the highest proteolytic activity contained mainly one protein making up more than $85 \%$ of the total protein content of this fraction. The same protein was purified from culture filtrates of $P$. lilacinus grown on eggs and on vitellin as substrate. It was concluded that all substrates induced this protein (Fig. 2), suggesting that this would be the serine protease.

\section{Characterization of protease}

The molecular mass of the serine protease of $P$. lilacinus was $33.5 \mathrm{kDa}$ by SDS-PAGE. Proteolytic activity including this $33.5 \mathrm{kDa}$ protein did not bind to a Mono $\mathrm{P}$ column at $\mathrm{pH} 10 \cdot 2$. Moreover, isoelectric focusing using gels of $\mathrm{pH}$ 3-10 showed that the protease focused at $\mathrm{pH} 10$ (data not shown), so the $\mathrm{pI}$ of the protein is above $\mathrm{pH} 10 \cdot 2$. The optimum $\mathrm{pH}$ and temperature for proteolytic activity was determined at $\mathrm{pH} 10.3$ and $60^{\circ} \mathrm{C}$, respectively. In order to elucidate the type of protease involved, a series of inhibitors, SH-reducing agents and various metal ions were tested for their effect on the activity of the purified protease. Most inhibitors tested did not significantly influence the proteolytic activity of the enzyme; PMSF, however, completely inhibited its activity. Consequently it was concluded the protease is of the serine protease class. Furthermore, the purified protease was capable of degrading insoluble vitellin and 
produced haloes on MM agar plates containing gelatin that were similar to those produced by $P$. lilacinus conidia (data not shown).

The N-terminal sequence of the enzyme was Ala-TyrThr-Gln-Gln-Pro-Gly-Ala-Pro-(His?/Cys?/Trp?)-GlyLeu-Gly-Arg-Ile-(Ser?), which showed some similarity to the $\mathrm{N}$-terminal sequence of other fungal serine proteases.

\section{Isolation and sequencing of protease CDNA clone}

In a PCR, primer $\mathrm{A}$, based on the $\mathrm{N}$-terminus of the mature protease, and primer $\mathrm{B}$, based on the conserved sequence surrounding the His residue in the catalytic site of serine proteases, amplified a single DNA fragment of $240 \mathrm{bp}$. To isolate a protease cDNA clone, this PCR reaction product was hybridized to a cDNA library, made from egg-induced mycelium. Of 100000 plaques, seven clones reacted with this probe. Restriction patterns of these clones were similar and the clone containing the largest insert (designated pSP-3) was selected for nucleotide sequence analysis. The sequence of cDNA clone pSP-3 encoded an ORF consisting of a putative protease and a part of the prosequence characteristic for most proteases. The signal-peptide sequence was not found in this clone. Southern hybridization revealed that the protease gene was present in only one copy per genome (data not shown). The amino acid sequence of the mature protease was compared with seven other subtilisin-like serine proteases from several organisms (Fig. 3). A large homology between the eight serine proteases was observed. In particular, strong homology was found in the amino acid stretches surrounding the three amino acids residues that constitute the active site of the enzyme (Asp-48, His-80 and Ser-252; numbering according to Fig. 3).

\section{Biological activity}

To study the involvement of the serine protease in the degradation of egg-shells by $P$. lilacinus we first tested binding of the purified protease to nematode eggs. The protease bound to the nematode eggs upon incubation at room temperature. Subsequently, the bound protease could be eluted from the eggs by washing in buffer containing $0.5 \mathrm{M} \mathrm{NaCl}$, as demonstrated by activity measurements and SDS-PAGE (data not shown). In addition, it was observed that after overnight incubation with the protease the eggs floated on the mixture, whereas control eggs incubated in medium without enzyme did not.

The effect of the protease on the development of individual eggs was further studied microscopically. Nematode eggs can be classified as either immature eggs (two-cell stage to gastrula stage) or eggs containing a juvenile (lima-bean stage to pretzel stage) (Tahseem et al., 1991). These two classes behaved quite differently upon treatment with protease. When the culture filtrate of $P$. lilacinus grown on vitellin was added to suspended nematode eggs, approximately $50 \%$ of the eggs hatched. However, immature eggs did not develop into eggs containing a juvenile or free-living juveniles. Therefore, the effects of the culture filtrate on (i) immature eggs, (ii) hatching of eggs containing a juvenile and (iii) mobility of hatched juveniles were evaluated separately.

Firstly, after treatment of immature eggs with the protease, three classes were observed: normal, abnormal and floating. The effect of culture filtrate and buffer on immature eggs was compared (Fig. 4). After $3 \mathrm{~d}$ of treatment with culture filtrate, egg suspensions contained approximately $70 \%$ of abnormal or floating eggs (including eggs with vacuoles, deformed, floating and broken eggs) in comparison to $10 \%$ in the control. After $6 \mathrm{~d}$ only a few normal eggs were left, while $90 \%$ of the eggs in the control remained healthy. Eggs treated with a commercial protease (isolated from Streptomyces caespitosus, Sigma) showed similar results to culture-filtrate-treated eggs (data not shown). Secondly, the percentages of hatched juveniles after treatment with culture filtrate or buffer were compared. At the various time points there was no statistical difference between the treatments. Therefore only the main effects of treatment were compared. The mean percentage of hatched juveniles over time in the enzyme-treated eggs $(63 \%)$ was significantly higher than that in the control $(50 \%)$ (data not shown). Thirdly, mobility of hatched juveniles was not visibly influenced by treatments. About $60 \%$ of the juveniles were still moving after $16 \mathrm{~d}$ (data not shown).

The development of four individual eggs in culture filtrate of $P$. lilacinus grown on vitellin as substrate (Fig. $5 a, b$ ), and in the control buffer (Fig. 5c, d) was studied. Vacuoles were observed in the culture-filtrate-treated eggs. In a subsequent bioassay, the effects of culture filtrate and of purified protease on the development of immature eggs were compared. The egg-masses used in this experiment behaved somewhat differently since $25 \%$ of the immature eggs did develop into eggs containing a juvenile. There was no significant difference in numbers of non-viable immature eggs after the first $3 \mathrm{~d}$ (Fig. 6). However, after $7 \mathrm{~d}$ significantly more non-viable eggs were found after enzyme treatment as compared to the control. After three weeks, $90-100 \%$ of the enzymetreated immature eggs were no longer viable. These observations suggest that the protease, which is also present in large amounts in the culture filtrate, is responsible for the increase in percentage of non-viable eggs.

\section{DISCUSSION}

Among parasitic fungi extracellular proteases are of widespread importance as tools for degrading structural components of their targets. Goettel et al. (1989) found high levels of a protease in the appressoria of Metarbizium anisopliae during the penetration of insect cuticles. LopezLlorca \& Robertson (1992) demonstrated the presence of a protease in appressoria of Verticillium sucblasporium during penetration of egg-shells by the plant-parasitic nematode Heterodera schachtii. Geremia et al. (1993) isolated a protease from the mycoparasitic fungus Trichoderma harzianum, which has been used as biocontrol agent. 


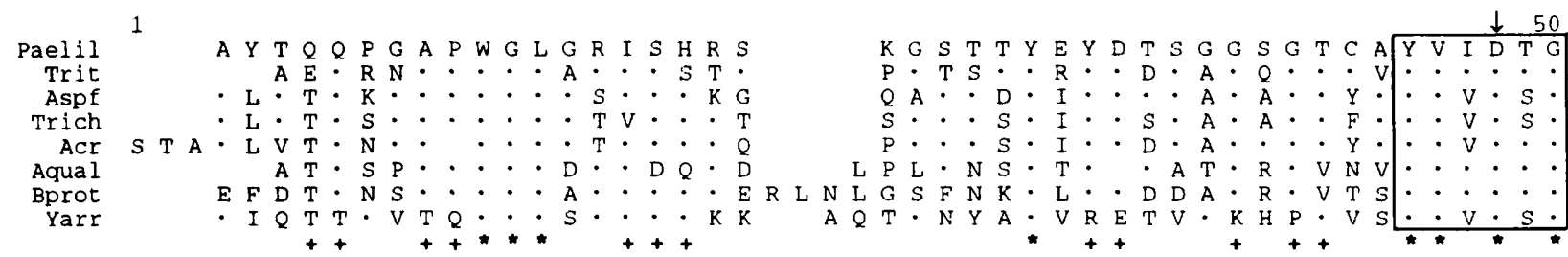

51 T 100 Paelil VEASH P E F E G R A S Q IKS F I S G Q N T D G N G H G TH C A G T I G S K T Y G V A K K T K

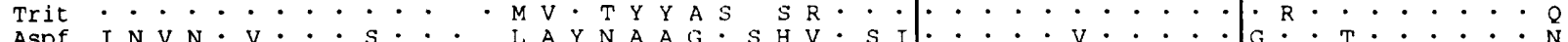
Aspf
Trich

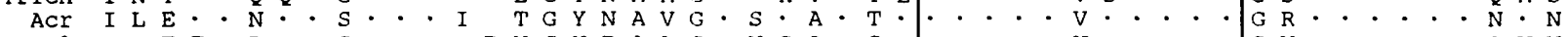

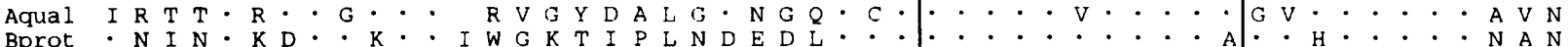

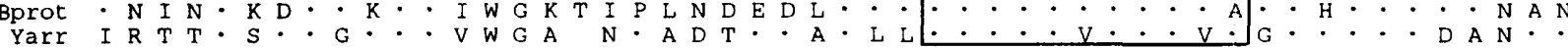

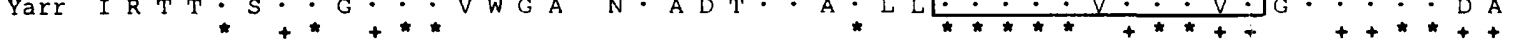

101

Paelil I Y G V K V L D N S G S G Y S G I I S G M D F A V Q D SKSR S C P K G V V

150

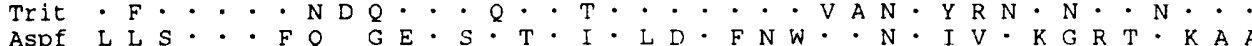

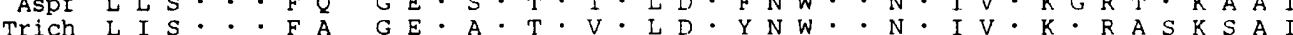

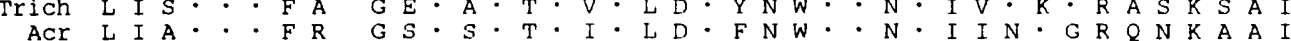

Aqual $\mathrm{L} \cdot \mathrm{A} \cdot \mathrm{R} \cdot \mathrm{C} N \cdot \cdot \mathrm{N} \cdot \mathrm{V} \cdot \mathrm{A} \cdot \mathrm{V} \cdot \mathrm{W} V \mathrm{~T} R \mathrm{R}$ H R R P A

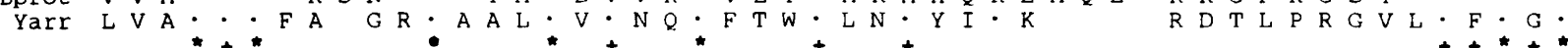

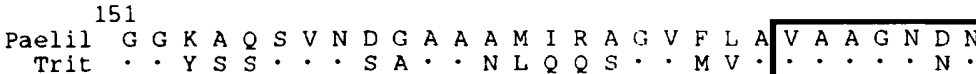

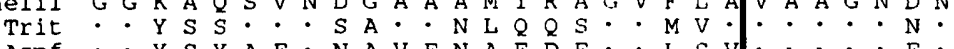

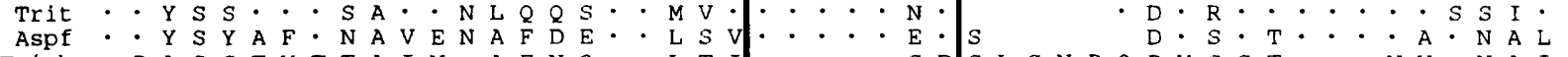

200

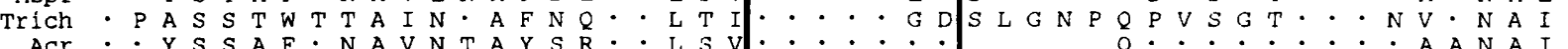

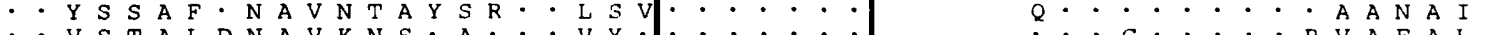

Aqual $:$. S P A L D I A V N A A E V I H F . . . E .

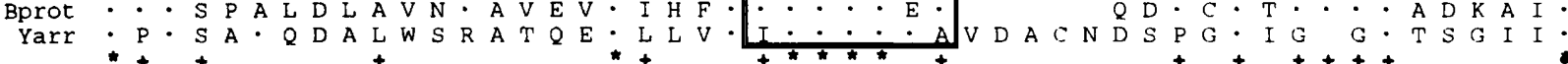

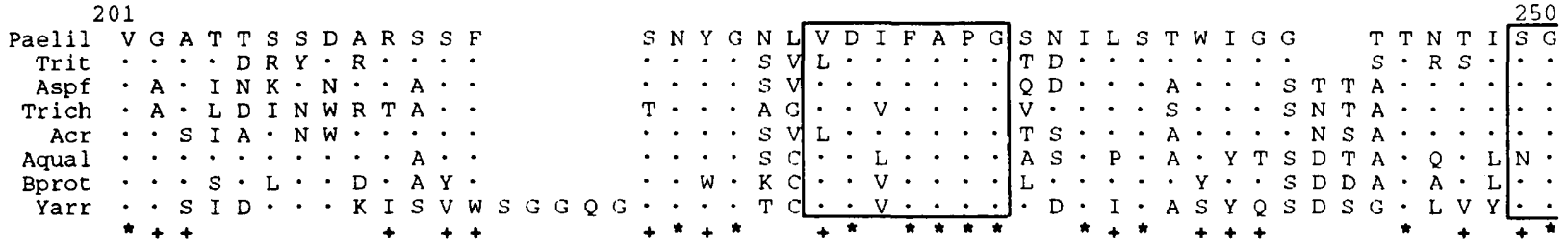

Paelil 251 T S M T P H IVGLG A Y L A G L E G F P

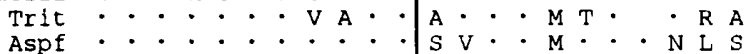

Aspf $: \therefore \cdot \therefore \mathrm{S} V \cdot \mathrm{M} \cdot \mathrm{M} \mathrm{L} \mathrm{S}$

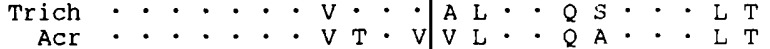

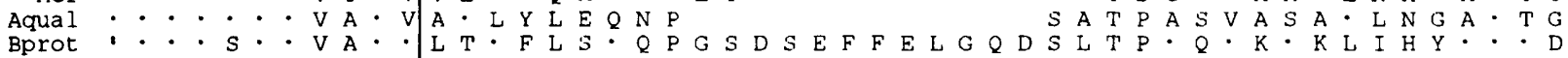

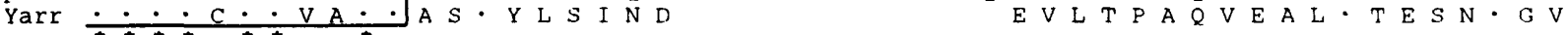

301

Paelil V L T G I P S G T V N Y L A F N G N P S G

350

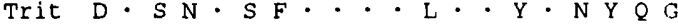

Aspf $\cdot \mathrm{V} \cdot \mathrm{N} \quad \mathrm{VK} \cdot \mathrm{S} \mathrm{P} \cdot \mathrm{K} \cdot \mathrm{Y} \cdot \cdot \mathrm{A}$

Trich R V . S S L N S P . V I I . . S S

ACr R V S N P G. S S P R I L Y . . G A

Aqual $R \cdot S \cdot$ G $\cdot$. S P R R L Y S L L S P . S G

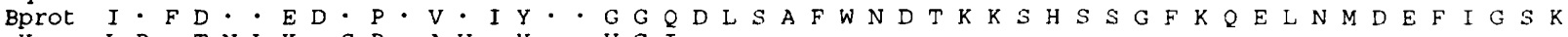

Yarr L P T T L K S P A V Y Y : V G I

G O A L C K R I Q T L S T K

T. S N A. R Y . A O T A N Q G

- PA.VTA. T K T . A. N G

$S P T \cdot V T N \cdot \cdot K A \cdot A \cdot S G$

TSG. A A L L N A $\cdot A \cdot T G$

$351 \quad 368$

Paelil

Trit

Aspf

Trich

Aqual

Bprot T D L I F D Q V R D I L D K L N I I

Yarr

Fig. 3. Comparison of amino acid sequence of mature subtilisin-like serine proteases. The mature protein sequence was aligned using the GCG Sequence Analysis Software Package (Devereux et al., 1984). Dots indicate identical residues as compared with the sequence of the $P$. lilacinus protease. Blanks are inserted for alignment. Conserved regions are boxed.

Stars indicate perfect matches; + signs indicate highly conserved residues. Arrows indicate the three amino acid residues 

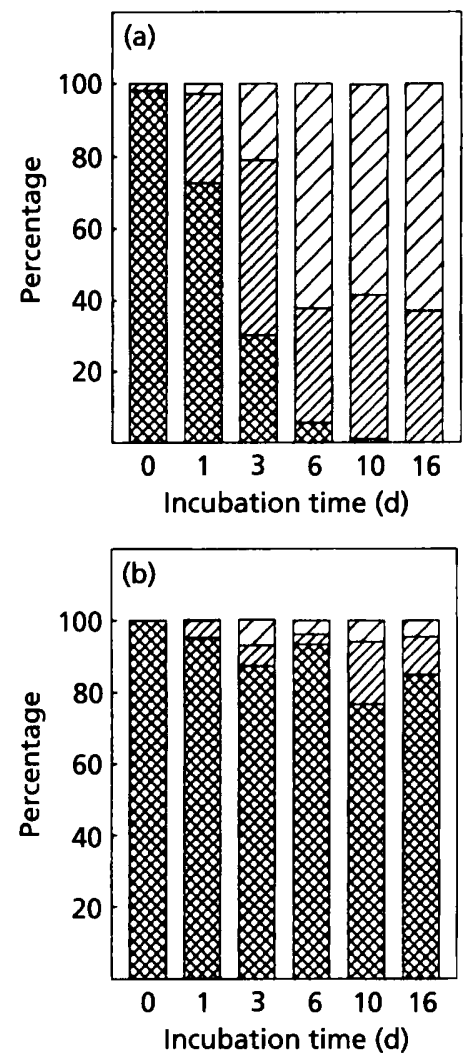

Fig. 4. Effect of (a) dialysed culture filtrate of $P$. lilacinus grown in $\mathrm{MM}$ with vitellin as substrate for $4 \mathrm{~d}$ and (b) control $(10 \mathrm{mM}$ potassium phosphate buffer $\mathrm{pH} \mathrm{6.0)}$ ) on immature eggs of $M$. hapla. The percentages of normal ( $(\nabla)$, abnormal $(\square)$ and floating (एZ) eggs after various periods of incubation are shown.

Proteases of the nematode-egg-parasitic fungus $P$. lilacinus were studied. Because it parasitizes eggs, the fungus needs to penetrate the egg-shell. This egg-shell consists of proteins (such as vitellin in the outer layer), chitin and lipids (Wharton, 1980). Consequently these compounds were added to the fungal growth medium to see whether specific enzymes were induced that are involved in degradation of the egg-shell or parts of it. In this study, emphasis was put on proteases involved in degrading the egg-shell of the root-knot nematode $M$. bapla. The induction of proteases by $P$. lilacinus in liquid medium supplemented with different substrates was studied over several days. The production of protease started $2 \mathrm{~d}$ after inoculation with conidia of the fungus. Vitellin appeared to be a very good substrate for the fungus. It also induced large quantities of proteolytic activity. Interestingly, SDSPAGE revealed a high degree of similarity between protein patterns present in culture filtrates of the fungus grown in MM containing either eggs or vitellin as substrate. This is in agreement with the hypothesis that the fungus has to degrade the vitellin layer of the egg-shell first and a protease is needed to degrade it. Specific protease activity was high in MM cultures containing eggs or vitellin as substrate (Table 1). Therefore, we conclude that the measured proteolytic activity was primarily induced by eggs or by a component of eggshells such as vitellin, and suggest that the protease present does indeed degrade egg-shells. This is in agreement with the SEM experiments, which showed involvement of lytic enzymes in the degradation of nematode eggs. The more eggs that were added to the medium, the higher the proteolytic activity in the culture filtrate. Chitin also appeared to be a good inducer of proteolytic activity, as was observed for $T$. harzianum by Geremia et al. (1993). These authors suggest a common induction pathway for chitinase and protease to explain the induction of both these enzymes by chitin. Simultaneous induction of chitinases and proteases also appears to occur in P. lilacinus since chitin also induced several chitinases (unpublished results). Protease was also produced in MM supplemented with $\mathrm{N}$ and $\mathrm{G}$, but only after all the added glucose was consumed and large amounts of mycelium was formed (Fig. 1). Moreover, daily addition of glucose to prevent glucose depletion resulted in complete repression of induction of protease activity. This only occurred when a $\mathrm{N}$-source was present in the medium. Repression by glucose was also reported for an extracellular protease excreted by Beawveria bassiana (Bidochka \& Khachatourians, 1988).

A subtilisin-like serine protease was partly purified from the culture filtrate of $P$. lilacinus grown on chitin as substrate. The protease was present in large amounts in the culture filtrate as shown by SDS-PAGE, and was responsible for most of the proteolytic activity present in the culture filtrate since the unbound fraction of the bacitracin-affinity column contained less than $10 \%$ of the total proteolytic activity. The same enzyme was purified from a culture grown on vitellin as substrate. Also, intact nematode eggs induced this protease. A cDNA clone encoding the serine protease was isolated and sequenced. The deduced amino acid sequence of the mature protease of $P$. lilacinus showed a large homology with that of other subtilisin-like serine proteases (see Fig. 3). This homology is especially evident in the regions surrounding the three residues, Asp-32, His-64 and Ser-221, in subtilisin BPN', composing the catalytic triad (Wells et al., 1983).

Serine proteases are widely distributed among fungi and are almost exclusively extracellular. Their molecular masses are commonly in the range $18.5-35 \mathrm{kDa}$ and they are optimally active at alkaline $\mathrm{pH}$ (North, 1982). Many proteases which play a role in pathogenesis are serine

that constitute the active site of the enzyme: Asp-48, His-80 and Ser-252. Paelil, serine protease of $P$. lilacinus; Trit, thermostable serine protease of Tritirachium album Limber (Samal et al., 1990); Aspf, alkaline protease of Aspergillus fumigatus (Jaton-Ogay et al., 1992); Trich, basic proteinase of T. harzianum (Geremia et al., 1993); Acr, alkaline protease of Acremonium chrysogenum (Isogai et al., 1991); Aqual, aqualysin I of Thermus aquaticus (Terada et al., 1990); Bprot, protease B of S. cerevisiae (Moehle et al., 1987); Yarr, alkaline extracellular protease of Yarrowia lipolytica (Davidow et al., 1987). 
(a)

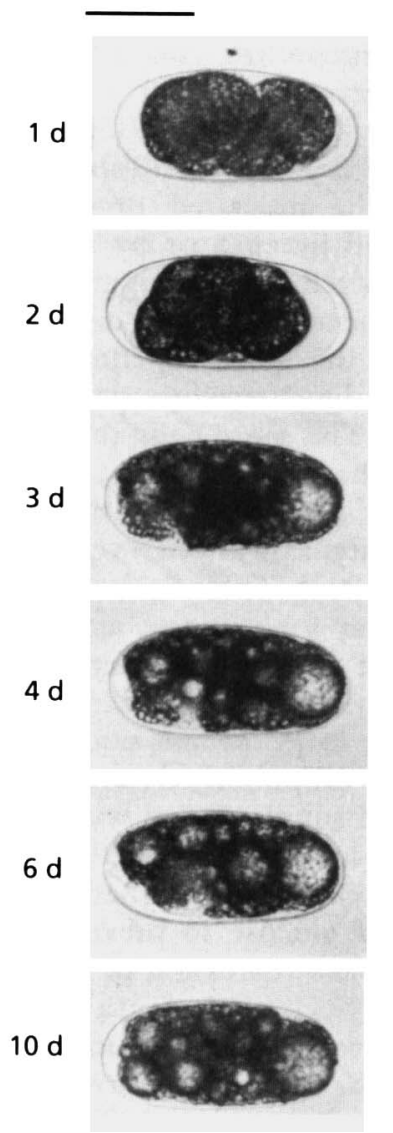

(b)

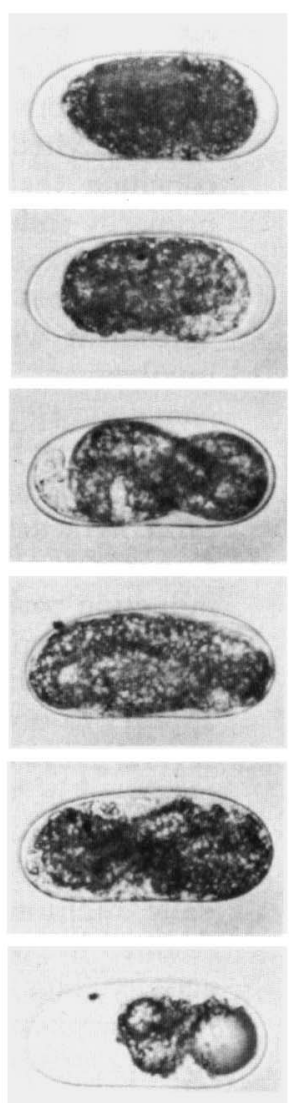

(c)

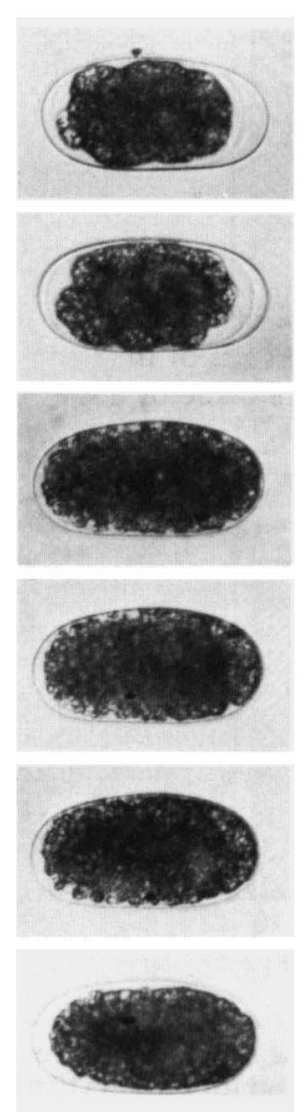

(d)

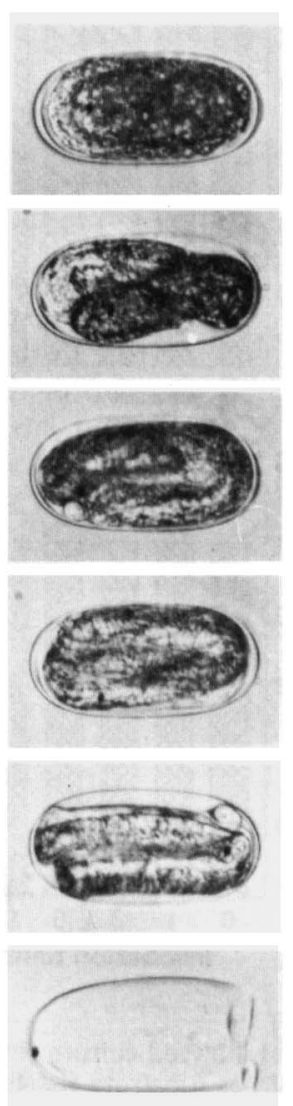

Fig. 5. Development of single eggs in culture filtrate of $P$. lilacinus grown in MM with vitellin as substrate for $4 \mathrm{~d}$ (a, b) and in the control (10 mM potassium phosphate buffer $\mathrm{pH} \mathrm{6.0)} \mathrm{(c,} \mathrm{d).} \mathrm{Photographs} \mathrm{were} \mathrm{taken} \mathrm{on} \mathrm{days} \mathrm{1,} \mathrm{2,} \mathrm{3,} \mathrm{4,} 6$ and 10. Bar, $40 \mu \mathrm{m}$.

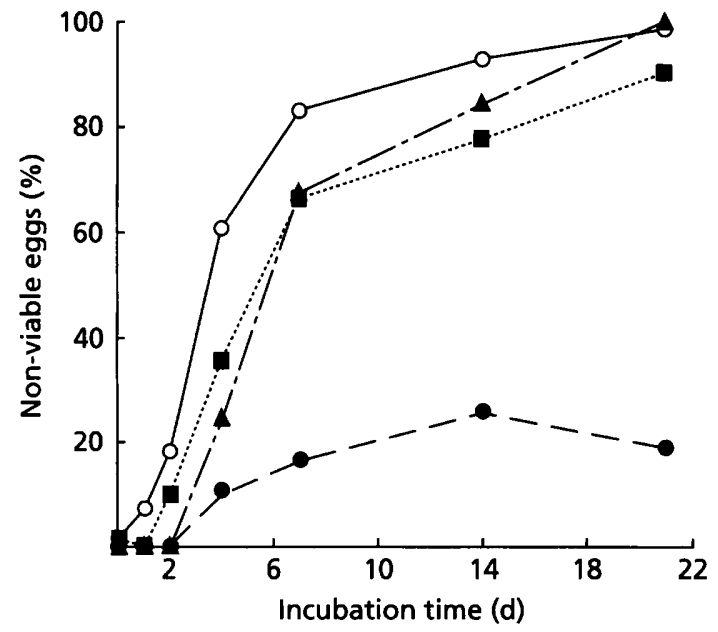

Fig. 6. Percentage of non-viable eggs of $M$. hapla after treatment with: protease purified from culture filtrate of $P$. lilacinus with vitellin as substrate $(\square)$; protease purified from culture filtrate of $P$. lilacinus with chitin as substrate $(\boldsymbol{A})$; dialysed culture filtrate of $P$. lilacinus with vitellin as substrate (O); and $10 \mathrm{mM}$ potassium phosphate buffer $\mathrm{pH} 6.0$ as control (O). proteases. This is in full agreement with the characteristics of the $P$. lilacinus serine protease.

The purified protease had a significant effect on nematode eggs. Incubation of nematode eggs with the enzyme resulted in binding of the protease to the eggs and ultimately in floating of the eggs. It would be of great interest to study binding characteristics in more detail.

The purified serine protease of $P$. lilacinus disturbed the development of root-knot nematode eggs. Our results show that the serine protease of $P$. lilacinus affects both eggs containing a juvenile as well as immature eggs of $M$. bapla. The hatching of the juveniles from the enzymetreated eggs was stimulated as compared with the control. This agrees with results from Mercer et al. (1992), who found increased hatch rates after incubation of eggs of M. bapla Chitwood with several plant and microbial chitinases. In contrast, Galper et al. (1990) found a lower hatching rate of Meloidogyne eggs treated with other enzyme solutions. It is difficult to compare these different enzymes in relation to their effect on hatching rate. An enzyme capable of degrading part of the egg-shell might expedite break-through of the shell causing premature hatching. Equal or lower hatching rates with different testing solutions can be ascribed to an incompatible 
enzymic effect on the eggs or a toxic effect on the juveniles. In our bioassays, mortality of the hatched juveniles was not significantly different from the control. This was confirmed in a test where hatched juveniles were exposed to a fresh protease solution (data not shown). Immature eggs were highly vulnerable to treatments with culture filtrate as well as with purified enzyme.

Similar data were obtained with a commercially obtained protease (from Streptomyces caespitosus), which is not a serine protease. Apparently the stage of development of the egg plays a decisive role in the results of the enzyme treatments. Similar observations were made by Jaworski et al. (1986), who found that chitinase treatment mainly affected younger eggs. Morgan-Jones \& RodriguezKabana (1985) found that immature eggs were more easily penetrated by fungal hyphae than eggs containing a juvenile. They suggested that the egg-shell layers of immature eggs are not yet fully developed.

\section{Concluding remarks}

Although the deleterious effect of culture-filtrate and proteases on eggs was evident, the mode of action of the enzyme is not understood. The effects we observed were disordering of the egg and death or disintegration of the embryos. We suggest that death of embryos is a result of a disturbed development. The most striking form of disordering of the eggs was the occurrence of vacuoles, which might cause the observed floating of the eggs.

The results of treatment of root-knot nematode eggs with the serine protease of $P$. lilacinus clearly suggest a crucial role of this enzyme in pathogenesis. Immunological and immunocytochemical studies should prove the role of the serine protease of $P$. lilacinus in pathogenicity.

\section{ACKNOWLEDGEMENTS}

The authors wish to thank Anne Voorpostel and Kees Langeveld for their help in performing some of the experiments, and Jaap Keijer for critically reading the manuscript. Special thanks go to Erik van Remortel and Joop de Bree for their statistical assistance.

\section{REFERENCES}

den Belder, E., Boekestein, A., van Esch, J. W. J. \& Thiel, F. (1993). Low-temperature scanning electron microscopy in fungusnematode interaction. Scanning 15, 37-42.

Bidochka, M. J. \& Khachatourians, G. G. (1988). Regulation of extracellular protease in the entomopathogenic fungus Beauveria bassiana. Exp Mycol 12, 161-168.

Bradford, M. M. (1976). A rapid and sensitive method for the quantitation of microgram quantities of protein utilizing the principle of protein-dye binding. Anal Biochem 72, 248-254.

Cabanillas, E. \& Barker, K. R. (1989). Impact of Paecilomyces lilacinus inoculum level and application time on control of Meloidogyne incognita on tomato. J Nematol 21, 115-120.

Cabanillas, E., Barker, K. R. \& Nelson, L. A. (1989). Growth of isolates of Paecilomyces lilacinus and their efficacy in biocontrol of Meloidogyne incognita on tomato. J Nematol 21, 164-172.
Dackman, C., Chet, I. \& Nordbring-Hertz, B. (1989). Fungal parasitism of the cyst nematode Heterodera schachtii: infection and enzymatic activity. Microb Ecol 62, 201-208.

Davidow, L. S., O’Donnell, M. M., Kaczmarek, F. S., Pereira, D. A., Zeeuw de, J. R. \& Franke, A. E. (1987). Cloning and sequencing of the alkaline extracellular protease gene of Yarrowia lipolytica. $J$ Bacteriol 169, 4621-4629.

Devereux, J., Haeberli, P. \& Smithies, O. (1984). A comprehensive set of sequence analysis programs for the VAX. Nucleic Acids Res 12, 387-395.

Dunn, M. T., Sayre, R. M., Carrell, A. \& Wergin, W. P. (1982). Colonization of nematode eggs by Paecilomyces lilacinus (Thom) Samson as observed with scanning electron microscope. Scanning Electron Microsc 3, 1351-1357.

Fitters, P. F. L. \& den Belder, E. (1993). A time-lapse technique to study the effect of fungal products on embryogenesis of nematode eggs. Meded Fac Landbouwwet Univ Gent 58/2b, 751-756.

Galper, S., Cohn, E., Spiegel, Y. \& Chet, I. (1990). Nematicidal effect of collagen-amended soil and the influence of protease and collagenase. Rev Nématol 13, 67-71.

Gaspard, J. T., Jaffee, B. A. \& Ferris, H. (1990). Meloidogyne incognita survival in soil infested with Paecilomyces lilacinus and Verticillium chlamydosporium. J Nematol 22, 176-181.

Genstat 5 Committee (1987). Genstat 5 Reference Manual. Oxford: Clarendon Press.

Geremia, R. A., Goldman, G. H., Jacobs, D., Ardiles, W., Vila, S. B., van Montagu, M. \& Herrera-Estrella, A. (1993). Molecular characterization of the proteinase-encoding gene, $p r b 1$, related to mycoparasitism by Tricboderma barzianum. Mol Microbiol 8, 603-613.

Goettel, M. S., St Leger, R. J., Rizzo, N. W., Staples, R. C. \& Roberts, D.W. (1989). Ultrastructural localization of a cuticledegrading protease produced by the entomopathogenic fungus Metarbizium anisopliae during penetration of host (Manduca sexta) cuticle. J Gen Microbiol 135, 2233-2239.

Isogai, T., Fukawa, M., Kojo, H., Kohsaka, M., Aoki, H. \& Imanaka, H. (1991). Cloning and nucleotide sequences of the complementary and genomic DNAs for the alkaline protease from Acremonium chrysogenum. Agric Biol Chem 55, 471-477.

Jany, K.-D., Lederer, G. \& Mayer, B. (1986). Amino acid sequence of proteinase $\mathrm{K}$ from the mold Tritirachium album Limber. FEBS Lett 199, 139-144.

Jatala, P., Kaltenbach, R., Bocangel, M., Devaux, J. \& Campos, R. (1980). Field application of Paecilomyces lilacinus for controlling Meloidogyne incognita on potatoes. J Nematol 12, 226.

Jaton-Ogay, G., Suter, M., Crameri, R., Falchetto, R., Fatih, A. \& Monod, M. (1992). Nucleotide sequence of a genomic and a cDNA clone encoding an extracellular alkaline protease of Aspergillus fumigatus. FEMS Microbiol Lett 92, 163-168.

Jaworski, E. G., Hemming, B. C., McPherson, S. A., Drahos, D. J., Lawson, E. C., Jonsson, C. B. \& Fuchs, R. L. (1986). Nematode control using soil bacteria. European Patent Application EP 171381.

Laemmli, U. K. (1970). Cleavage of structural proteins during the assembly of the head of bacteriophage T4. Nature 227, 680-685.

Lingappa, Y. \& Lockwood, J. L. (1962). Chitin media for selective isolation and culture of Actinomycetes. Phytopatbol 52, 317-323.

Lopez-Llorca, L. V. (1990). Purification and properties of extracellular proteases produced by the nematophagous fungus Verticillium suchlasporium. Can J Microbiol 36, 530-537.

Lopez-Llorca, L. V. \& Robertson, W. M. (1992). Immunocytochemical localization of a $32-\mathrm{kDa}$ protease from the 
nematophagous fungus $V$ erticillium sucblasporium in infected nematode eggs. Exp Mycol 16, 261-267.

McCullagh, P. \& Nelder, J. A. (1989). Generalized Linear Models, 2nd edn. London: Chapman \& Hall.

Mercer, C. F., Greenwood, D. R. \& Grant, J. L. (1992). Effect of plant and microbial chitinases on the eggs and juveniles of Meloidogyne bapla Chitwood (Nematoda: Tylenchida). Nematologica 38, 227-236.

Moehle, C. M., Tizard, R., Lemmon, S. K., Smart, J. \& Jones, E. W. (1987). Protease B of the lysosome-like vacuole of the yeast Saccharomyces cerevisiae is homologous to the subtilisin family of serine proteases. Mol Cell Biol 7, 4390-4399.

Morgan-Jones, G. \& Rodriguez-Kabana, R. (1985). Phytonematode pathology: fungal modes of action. A perspective. Nematropica 15, 107-114.

Morgan-Jones, G., White, J. F. \& Rodriguez-Kabana, R. (1983). Phytonematode pathology: ultrastructural studies. I. Parasitism of Meloidogyne arenaria eggs by Verticillium chlamydosporium. Nematropica 13, 245-260.

Morrissey, J. H. (1981). Silver stain for proteins in polyacrylamide gels : a modified procedure with enhanced uniform sensitivity. Anal Biochem 117, 307-310.

North, M. J. (1982). Comparative biochemistry of the proteinases of eucaryotic microorganisms. Microbiol Rev 46, 308-340.

Rinderknecht, H., Geokas, M. C., Silverman, P. \& Haverback, B. J. (1968). A new ultrasensitive method for the determination of proteolytic activity. Clin Chim Act 21, 197-203.

Samal, B. B., Karan, B., Boone, T. C., Osslund, T. D., Chen, K. K. \& Stabinsky, Y. (1990). Isolation and characterization of the gene encoding a novel, thermostable serine proteinase from the mould Tritiracbium album Limber. Mol Microbiol 4, 1789-1792.

Sambrook, J., Fritsch, E. F. \& Maniatis, T. (1989). Molecular Cloning: a Laboratory Manual, 2nd edn. Cold Spring Harbor, NY: Cold Spring Harbor Laboratory.

Stepanov, V. M. \& Rudenskaya, G. N. (1983). Proteinase affinity chromatography on bacitracin-Sepharose. J Appl Biochem 5, $420-428$.

Stirling, G. R. \& Mankau, R. (1979). Mode of parasitism of Meloidogyne and other nematode eggs by Dactylella oviparasitica. J Nematol 11, 282-288.

Tahseem, Q. M., Shamim, J. \& Ahmad, I. (1991). Observations on the immature and post-immature development of Diploscapter orientalis (Nematoda: Rhabditida). Rev Nématol 14, 251-260.

Terada, I., Kwon, S.-T., Miyata, Y., Matsuzawa, H. \& Ohta, T. (1990). Unique precursor structure of an extracellular protease, aqualysin $\mathrm{I}$, with $\mathrm{NH}_{2}{ }^{-}$, and $\mathrm{COOH}$-terminal pro-sequences and its processing in Escherichia coli. J Biol Chem 265, 6576-6581.

Wells, J. A., Ferrari, E., Henner, D. J., Estell, D. A. \& Chen, E. Y. (1983). Cloning, sequencing and secretion of Bacillus amyloliquefaciens subtilisin in Bacillus subtilis. Nucleic Acids Res 11, 7911-7925.

Wharton, D. (1980). Nematode egg-shells. Parasitology 81, 447-463.

Zaki, F. A. \& Bhatti, D. S. (1990). In vivo parasitism of Meloidogyne javanica by an oviparasitic fungus, Paecilomyces lilacinus. Nematol Mediter 18, 141-143.

Received 12 September 1994; revised 9 December 1994; accepted 16 December 1994 